\title{
Update on Gene Therapy as an Antineoplastic Alternative
}

\author{
Carlos Miguel Campos Sanchez*, Laura Adalys Guillen Leon, Isbety Acosta Escanaverino Daniel \\ Rodriguez Hurtado and Ana Beatriz Sanchez Cabrera
}

Hospital Celestino Hernández Robau, Universidad de Ciencia, Cuba

\begin{abstract}
The $21^{\text {st }}$ century has revolutionized medicine and with it the emergence of new treatment trends and the improvement of others not so new where gene therapy is found; an alternative that is gaining space in the profiles of cancer therapy. With the aim of describing the main characteristics of gene modification techniques and their use in cancer treatment or as an adjuvant in traditional treatments, 35 bibliographic references were reviewed where it was pointed out that: even though cancer is a monogenic disease, it is one of the main targets for this practice. The main techniques are aimed at strengthening our body and promoting neoplastic self-destruction in different ways. Gene therapy is an antineoplastic alternative that, although it is not a cure, promises to obtain very good results in the future.
\end{abstract}

KEYWORDS: Gene therapy; Treatment; Cancer

\section{INTRODUCTION}

When talking about cancer, it refers to a group of diseases characterized by the rapid proliferation of abnormal cells [1] and is characterized by spontaneous and uncontrolled cell growth and multiplication, and which is the result of the phenotypic genotypic transformation of the normal cell; it tends to invade surrounding tissue and is therefore capable of metastasizing [2].

Another of the properties of cancer that gives it its great malignancy is the formation of new blood vessels, an essential stage for the establishment and growth; therefore, angiogenesis has become important as a target base for many treatments [2]. On the other hand, multiple oncogenes and tumor suppressor genes that participate in tumor initiation and progression have been described. In this sense, two possible patterns of cell proliferation can be distinguished: Stochastic model: the somatic cell is the one that presents the mutation and, of this, an uncontrolled division with accumulation of new genetic alterations until reaching the tumor state. Each tumor cell shares the same characteristics and can form new primary tumors. Hierarchical model: tumor formation begins with a tumor stem cell, which explains the cellular heterogeneity present in neoplastic processes from the cellular differentiation of daughter cells. It seems clear that the tumor stem cell is present in multiple histological types of cancer, including leukemia, brain tumors, breast cancer, and it is proposed that it could be present in all cell types [3]. Since the discovery of cancer to the present day [4] there have been multiple treatment alternatives, but many have the tumor stage as a drawback [5].

In recent years, the great advances in biotechnology and cybernetics are allowing the search and functional characterization of many genes contained in the cell [6], which has made it possible to conceive the primordial molecular processes that cause the transformation of a normal cell into a tumor cell, together that it has allowed the development of highly sophisticated and individualized diagnostic and therapeutic methodologies according to the molecular biological profile of the patient's tumor. Gene therapy is one of the main alternatives and with promising results in the treatment of cancer. It involves the treatment of a disease by transmitting gene material to specific cells of a patient in order to correct, activate or generate a new activity [7].

Although the beginnings of gene therapy date back to 1980, when Martin Cline made an unsuccessful attempt to cure two patients with thalassemia using this technique without prior authorization, the approval of the first clinical protocol with the insertion of a gene into a human being was made in January 1989. The application was submitted by Anderson, Blaese and Rosenberg and was not properly a gene therapy. In September 1990, the same authors conducted the first successful gene therapy
Quick Response Code:

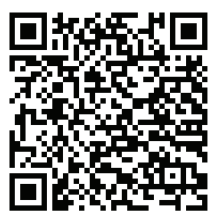

Address for correspondence: Carlos Miguel Campos Sanchez, Hospital Celestino Hernández Robau, Universidad de Ciencia, Cuba

Received: April 09, $2021 \quad$ Published: April 23, 2021

How to cite this article: Carlos MCS, Laura AGL, Isbety AEDRH, Ana BSC. Update on Gene Therapy as an Antineoplastic Alternative. 2021- 3(2) OAJBS.ID.000271. DOI: 10.38125/ OAJBS.000271 
clinical trial; the patient was a 4-year-old girl with adenosine deaminase deficiency, a very rare recessive disease that causes severe combined immunodeficiency. The treatment consisted of introducing the gene, and although the results were positive and the girl could lead a normal life since then, the treatment required to be repeated. Since then, hundreds of patients have received gene therapy for various conditions around the world. In recent years, trials have been conducted for some inherited disorders such as cystic fibrosis, familial hypercholesterolemia, Gaucher disease, and Cancer. However, it is necessary to bring up another element to close the gap between gene therapy as a therapeutic option and as an ethical controversy [8].

\section{OBJECTIVE}

To describe the main characteristics of gene modification techniques and their use in cancer treatment or as an adjuvant in traditional treatments.

\section{DEVELOPING}

Gene therapy is an alternative therapy to conventional drugs for the treatment of inherited, acquired, infectious or metabolic genetic diseases. We can differentiate two types of gene therapy according to the cells on which it acts [7]. Somatic gene therapy: consists of the insertion of functional genes that are absent in the individual. It is carried out in all the cells and tissues of the body with the aim of treating a disease or making a labeling, so that the modifications introduced, if they manage to last in the cell, are not heritable and only take place in said patient.

\section{Germinal Gene Therapy}

On the other hand, it causes the gene expression of the administered genetic material to be maintained in the offspring. Currently there are many ethical and legal conflicts with this type of gene therapy in germ cell lines, so it is not allowed. Until 2016, 2356 approved gene therapy clinical trials have been reported being carried out or completed in the world, the clinical protocols of Gene Therapy that have been carried out have been somatic therapy, [9] germ therapy is not authorized in any country, since an offspring with beneficial characteristics would be created over the rest of the people, who did not benefit from the therapy [10]. The forms of administration that exist in gene therapy are In Vivo and Ex Vivo therapies.7.9.14 The one that obtains the best results is Ex Vivo therapy [7].

An Ex Vivo approach involves the transduction of cells in culture followed by the injection of these modified cells into the target tissue. The genetically modified cells secrete the desired protein at the injection site. An advantage of this approach is the possibility of using non-viral vectors. Although this method results in a relatively low transfer efficiency, untransformed cells can be easily selected. Furthermore, cells can be well characterized and expanded before transplantation. Cells used for Ex Vivo gene therapy must be easily accessible and able to survive for longer periods of time in vitro without significantly changing their phenotype.

In vivo gene delivery involves the direct introduction of vectors, usually viruses. In Vivo administration minimizes manipulation of the target cell population by directly delivering these cells into their current environment. There are two main disadvantages: an immune response of the host towards the vector and infected cells, and the inability of most vectors to become unshakable in the host genome. Vectors used in gene therapy are varied but can be classified as viral or not. Therapeutic targets have been summarized with essentially four potential mechanisms [11-13].

\section{Compensation Mutation}

An attempt is made to correct causal molecular lesions for malignant transformation. Molecular chemotherapy: Selective delivery or propagation of gene products toxic to cancer or tumor stromal cells. Genetic immunoenhancement: Achieve active immunization against tumor-associated antigens by gene transfer either in tumor cells or cellular components of the immune system. Virus-mediated oncolysis: Viral vectors with conditional replication in tumor cells exerting oncolysis with direct cytopathic effects. According to the type of disorder, gene therapy is performed through one of the following approaches [14].

\section{Gene Addition}

Consists of introducing a correct copy of the functional gene so that it produces the corresponding protein in adequate quantities in the tissue to be treated. It is the most used procedure.

\section{Gene Correction}

Seeks to correct the altered gene by replacing it with the correct gene through homologous recombination, although at the moment this method is not very efficient. Instead, it is possible to exchange a specific mutated nucleotide, which is useful for treating diseases with point mutations.

\section{Gene Suppression}

Consists of reducing the expression of a certain gene, which is achieved through the use of interference RNA (shRNA) that induces the degradation or silencing of the target messenger RNA (mRNA). On the other hand, Hernández-Alcoceba proposes a schematization based on the function of therapy [11].

\section{Transfer of Tumor Suppressor Genes}

The treatment can affect the base of the cancer and inhibit the expression of oncogenes or transfer correct copies of tumor suppressor genes that have had deletions or mutations. In this way, tumor cells regain their response to pro-apoptotic stimuli, and they become more sensitive to chemotherapy.

\section{Transfer of Cytotoxic Genes}

By using selective routes of administration or modifications of the tropism of the vectors (targeting), it is possible to achieve a relatively specific transfer of genes into tumor cells. This allows the introduction of "suicide" genes that by various mechanisms (apoptosis, necrosis) cause destruction.

\section{Angiogenic Inhibition}

Certain polypeptides, such as angiostatin, endostatin, and others, have been shown to inhibit the formation of new vessels in tumors and control their growth.

\section{Gene Immunotherapy}

Stimulation of the immune response against cancer cells. Modulation of the immune response to a neoplasm is one of the most promising aspects of the previously described strategies, this as in T-cell immunotherapy, for example, with a growing number of clinical trials related to CAR (chimeric antigen receptor) [14]. 


\section{Virotherapy}

The so-called oncolytic viruses are those that, either naturally or through genetic modifications, cause preferential destruction of tumor cells over normal cells [11]. The number of open cancer studies registered is increasing rapidly; As of December 2015, there are more than 200 protocols with the enrollment of more than 8000 patients worldwide. Approximately $40 \%$ of the protocols address the use of CAR $\mathrm{T}$ cells with the majority of trials (85\%) being conducted in the US and China. About $65 \%$ of studies are directed against hematologic malignancies [15].

There are several drugs under study that use gene therapy as the basis of treatment. Among them, those aimed at treating breast cancer [16], hepatocarcinoma [11], melanomas [17], uterine sarcoma $[20,21]$ and others stand out.

Talimogene laherparepvec (T-VEC) is a drug with a basis in oncolytic therapy, it is a virus established from herpes simplex type 1 and its functionality is studied in the treatment of melanoma [1720]. Clinical studies express that T-VEC increases the local immune response even distant.

Gendicine is a drug that is combined with traditional chemotherapy and according to a study in Japan it is used with good results in uterine sarcoma [21,22]. The drug is based on a p53 prototype administered with an adenovirus vector [23].

Stimuvax or L-BLP25 is a liposomal vaccine based on a 25 amino acid synthetic peptide containing the repetitive sequence of the MUC1 extracellular domain, attached to a lipid structure (cholesterol, dimyristoyl phosphatidylglycerol and dipalmitoyl phosphatidylcholine) and lipid A as an adjuvant. IgM and IgG antibodies against MUC1 have been found in the sera of healthy multiparous women; possibly generated by an increase in MUC1 production during pregnancy and lactation, and these antibodies are believed to have a protective effect capable of reducing the risk of breast cancer. It is worth noting that MUC1 is aberrantly glycosylated in cancer cells, so its structure differs widely from that expressed in normal cells, so an antibody directed against the aberrant MUC1 of the cancer cell may not affect normal tissue $[1,24]$.

Ipilimumab (anti-CTLA-4) is a recombinant human monoclonal antibody (IgG1 kappa immunoglobulin) approved by the Food and Drug Administration (FDA) in 2011 for the treatment of metastatic melanoma. The human monoclonal antibody nivolumab (antiPD-1) is an IgG4 kappa immunoglobulin licensed in Japan in 2014 for the treatment of unresectable melanoma. The FDA approved the humanized monoclonal antibody pembrolizumab (IgG4 kappa immunoglobulin) against PD-1 in September 2014 and nivolumab in December 2014, both for the treatment of advanced melanomas. In March 2015, the FDA approved nivolumab for the treatment of lung cancer [25].

MUC_1 is another of the drugs this is a transmembrane glycosylated protein in the normal cell is expressed only in the apical portion of the epithelial cells but in the cancer cell it is expressed up to 100 times more and with generally abnormal glycosylation; So far, three variants of vaccines have been developed with MUC_1 antigen based on vaccinia virus, dendritic cell and DNA vaccine. All with encouraging results for breast cancer [26,27].

Other new drugs are currently being discussed and with promising achievements, this is the case of Poxvirus JX-594, which is an oncolytic virus used in hepatocellular carcinoma [28,29], NYESO-1 [30], Trastuzumab [31,32], Anti VEGF [33] and Bevacizumab $[34,35]$.

\section{CONCLUSION}

Gene therapy has gained extraordinary value in the treatment of cancer in the last decade, although it is not yet the cure for this pathology, more and more protocols are approved and with encouraging results. The main techniques are aimed at strengthening our body and promoting neoplastic self-destruction in different ways.

\section{REFERENCES}

1. Sarmiento R, Adriana L (2015) Antígenos asociados a tumores y su potencial uso en el tratamiento del cáncer. Salud Uninorte 31(1): 118137.

2. Hernandez DE (2016) Biología del cancer de mama. Rev Venez Oncol 28(3): 188-200.

3. Bosch BJ, López PGJM, García FLJ, Prósper CF (2007) Célula madre y cáncer: dilucidando el origen de la célula madre tumoral. Rev Med Univ Navarra 51(2): 14-17.

4. Real Arribas FX (2016) Genes, Herencia y Cancer. En Farreras Rozman Medicina Interna 1191-1202.

5. NCCN (2019) Clinical practice guidelines in oncology. Version 2.

6. Romero MM, Mendieta EJL, Sánchez GMV, Alonso C, Clemente MO, et al., (2019) Oncología personalizada: Principales biomarcadores en el pronóstico y tratamiento de tumores sólidos. Rev del Lab Clínic 12(3): e1-e8.

7. Ilarduya CT, Fructuoso M, Blanco L (2018) Nuevas formulaciones farmacéuticas basadas en la nanotecnología dirigidas al tratamiento del cáncer mediante estrategias de terapia génica. In Anales de la Real Academia Nacional de Farmacia 84(1): 72-85.

8. Agurres Fernadez RE, Serra Valdez MA, Agurre PE (2017) Vision holística de nuevos desafíos: paradigmas tecnológicos y fundamentos bioéticos de la medicina futurista. Revista Habanera de Ciencia Médicas 16 (5): 839 -849.

9. Morales GF (2018) Terapia génica en el arsenal de terapéutica de la enfermedad oncológica. Revista Clínica de la Escuela de Medicina de la Universidad de Costa Rica 8(1): 1-6.

10. Juan BA, García D (2016) Terapia génica en línea germinal: Aspectos científicos y éticos. Etica de la investigación de las enfermedades raras: 149-162.

11. Hernández AR, Prieto VJ (2009) Tratamiento génico de la hepatocarcinoma. Gh Continuada. Septiembre-octubre 8(5): 261-266.

12.Adriaansen J, Vervoordeldonk MJBM, Tak PP (2006) Gene therapy as a therapeutic approach for the treatment of rheumatoid arthritis: innovative vectors andtherapeutic genes. Rheumatology 45(6): 656668.

13. Annan AC, Fisher PB, Dent P, Siegal GP, Curiel DT, et al., (2017) Gene therapy in the treatment of human cancer. In: Cole man WB, Tsongalis GJ [Eds.], The Molecular Basis of Human Cancer: 811-841.

14. Gutiérrez VJ, Cardona GGP (2017) Terapia génica en enfermedades neurodegenerativas y demencia post infarto cerebral: perspectiva de traslación. Revista de la Academia Colombiana de Ciencias Exactas, Físicas y Naturales 41(158): 6-21.

15. Almåsbak H, Aarvak T, Vemuri MC (2016) Car T cell therapy: A game changer in cancer treatment. J Immunol Res 2016: 1-10.

16. Prieto AV (2019) Cáncer de mama: tratamientos inmunológicos. Clínica. (27): 33-41.

17. Andtbacka RH, Ross M, Puzanov I, Milhem M, Collichio F, et al., (2016) Patterns of clinical response with talimogene laherparepvec (T-VEC) 
in patients with melanoma treated in the OPTiM phase III clinical trial. Annals of Surgical Oncology 23(13): 4169-4177.

18. Long GV, Dummer R, Ribas A, Puzanov I, Vander Walde A, et al., (2016) Efficacy analysis of MASTERKEY-265 phase 1b study of talimogene laherparepvec (T-VEC) and pembrolizumab (pembro) for unresectable stage IIIB-IV melanoma.

19. Haitz K, Khosravi H, Lin JY, Menge T, Nambudiri VE, et al. (2020) Review of talimogene laherparepvec (T-VEC): A first in class oncolytic viral treatment of advanced melanoma. J Am Acad Dermatol 83(1): 189-196.

20. Johnson DB, Puzanov I, Kelley MC (2015) Talimogene laherparepvec (T-VEC) for the treatment of advanced melanoma. Immunotherapy 7(6): 611-619.

21. Redd BKE, Lu P, Vander MER, Lim CS (2019) Advances in delivery vectors for gene therapy in liver cancer. Therapeutic Delivery 11(1): 833-850.

22. Xia Y, Wang L, Ma X, Li X (2020) Investigation on the genomic characterization of uterine sarcoma for rAd-p53 combined with chemotherapy treatment. Human Gene Therapy 31(15-16): 881-890.

23. Pascual T Abstract OT0-01-01:SOLTI-1503 PROMETEO: Combination of talimogen laherparepvec (T-VEC) with atezolizumab in patient with residual breast cancer after standart neoadjuvant multi-agent chemotherapy.

24. Bjelic RV, Singer CF, Pfeiler G, Hubalek M, Bartsch R, et al., (2017) 209P Quality-of-life results from a randomized, phase-II-study of the therapeutic cancer vaccine L-BLP25 (Stimuvax®) in the preoperative treatment of women with primary breast cancer (ABCSG-34). Annals of Oncology.

25. Rangel SMM, Aguilar CE, Rojas MA (2017) Inmunoterapia y terapia génica como nuevos tratamientos contra el cáncer. Colombia Médica 48(3): 138-147.

26. Yang C, Murray JL, Ibrahim NK (2018) MUC1 and cancer immunotherapy. In Immunology : 225-240.
27. Hossain MK, Wall KA (2016) Immunological evaluation of recent MUC1 glycopeptide cancer vaccines. Vaccines 4(3): 25.

28. Cho E, Ryu EJ, Jiang F, Jeon UB, Cho M, et al. (2018) Preclinical safety evaluation of hepatic arterial infusion of oncolytic poxvirus. Drug Des Devel Ther 12: 2467-2474.

29. Yoo SY, Badrinath N, Woo HY, Heo J (2017) Oncolytic virus-based immunotherapies for hepatocellular carcinoma. Mediators of inflammation.

30. Angelo SP, Melchiori L, Merchant MS, Bernstein D, Glod J, et al., (2018) Antitumor activity associated with prolonged persistence of adoptively transferred NY-ESO-1 c259T cells in synovial sarcoma. Cancer discovery 8(8): 944-957.

31. Jacobs SA, Robidoux A, Abraham J, Pérez GJM, La Verde N, et al. (2020) Correction to: NSABP FB-7: a phase II randomized neoadjuvant trial with paclitaxel+ trastuzumab and/or neratinib followed by chemotherapy and postoperative trastuzumab in HER2+ breast cancer. Breast Cancer Research 22(1): 1-2.

32. Krikez I, Benmalek R, Bennouna G, Drighil A, Azzouzi L, et al., (2020) Reversibility of trastuzumab induced cardiotoxicity in breast cancer patients: A prospective observational study. Archives of Cardiovascular Diseases Supplements 12(1): 42.

33. Horikawa N, Abiko K, Matsumura N, Baba T, Hamanishi J, et al., (2020) Anti-VEGF therapy resistance in ovarian cancer is caused by GM-CSFinduced myeloid-derived suppressor cell recruitment. British J Cancer 122: 778-788.

34. Ron DA, Labandeir CM, García SC, Mata JG, Fernández MS, et al., (2020) Sustained stable disease with capecitabine plus bevacizumab in metastatic appendiceal adenocarcinoma: A Case report. Case Reports in Oncology 13(1): 69-75.

35. Halperin DM, Liu S, Dasari A, Fogelman DR, Bhosale P, et al., (2020) A phase II trial of atezolizumab and bevacizumab in patients with advanced, progressive neuroendocrine tumors (NETs); 38(4). 